\title{
B17 - PURIFICAÇÃO E CARACTERIZAÇÃO DE ASPARAGINASE II DE Saccharomyces cerevisiae CLONADA EM Pichia pastoris: ESTUDO DE UM POSSÍVEL FÁRMACO ANTILEUCÊMICO
}

Luciana Facchinetti de Castro Girão ${ }^{1,2 *}$, Surza Lucia Gonçalves da Rocha ${ }^{2}$, Ricardo Sobral Teixeira ${ }^{1}$, Maria Antonieta Ferrara ${ }^{3}$, Jonas Perales ${ }^{2}$, Elba Pinto da Silva Bon ${ }^{1, *}$

${ }^{1}$ Instituto de Química, Universidade Federal do Rio de Janeiro

${ }^{2}$ Laboratório de Toxinologia, Instituto Oswaldo Cruz, Rio de Janeiro, Brasil

${ }^{3}$ Instituto de Tecnologia em Fármacos, Fiocruz , Rio de Janeiro, Brasil

Introdução: Asparaginases bacterianas oriundas de Escherichia coli e Erwinia chrysanthemi são utilizadas como medicamentos para tratamento de leucemia linfocítica aguda e linfomas não Hodgkin. Apesar das propriedades terapêuticas destas enzimas, reações adversas têm sido relatadas: por vezes tão severas que impossibilitam a utilização destes medicamentos por alguns pacientes. Além disso, o único medicamento que o Brasil importava parou de ser produzido. Tendo em vista esses dois aspectos, propôs-se a produção de asparaginase de fonte não bacteriana.

Objetivo: Purificar e caracterizar a asparaginase II de Saccharomyces cerevisiae clonada e expressa em Pichia pastoris visando à produção de um fármaco antileucêmico.

Metodologia: A metodologia estabelecida para a purificação da asparaginase recombinante envolveu três etapas: ultrafiltração em membrana Amicon de $50 \mathrm{kDa}$, cromatografia de exclusão molecular em coluna Superdex200 e cromatografia de troca aniônica em coluna Mono-Q. A homogeneidade foi confirmada através de SDS-PAGE em condições redutoras e por espectrometria de massas do tipo MALDI-TOF/TOF; a atividade enzimática foi determinada pela reação de hidroxilaminólise. O ponto isoelétrico foi estimado por eletroforese bidimensional e a massa molecular foi determinada utilizando SDS-PAGE $12 \%$ e cromatografia de exclusão molecular. A porção glicídica da asparaginase recombinante em sua forma homogênea foi analisada através de SDS-PAGE 12\% em condições redutoras, seguido de coloração pela técnica de ácido periódico/reagente de Schiff. Além disso, realizamos a clivagem enzimática dos glicídios N-ligados com PNGase $\mathrm{F}$ à $37{ }^{\circ} \mathrm{C}$ por 3 horas, seguido de análise por SDS- 
PAGE. Caracterizou-se o $\mathrm{pH}$ e a temperatura ótima da enzima por reação de hidroxiaminólise em diferentes valores de $\mathrm{pH}$ e temperatura.

Resultados: A fração homogênea oriunda da troca aniônica apresentou atividade específica de 204 UI mg ${ }^{-1}$, representando um grau de purificação de 10,9 vezes e uma recuperação de atividade de 51,3 \% em relação ao extrato bruto. Após eletroforese, observamos a presença de duas bandas, com massa molecular estimada em 48 e 46 kDa respectivamente. Após análise por espectrometria de massas, verificamos que estas bandas correspondem à enzima asparaginase II de S. cerevisiae. As duas bandas apresentaram coloração positiva para glicosilação. A massa molecular da enzima nativa foi estimada em $136 \mathrm{kDa}$, sugerindo que a enzima é um oligômero. No entanto, foram observados dois valores de pH ótimo em 7,2 e 9,0. Após clivagem enzimática dos glicídios por PNGase F, as duas bandas migraram como uma única banda em SDSPAGE, indicando que a principal diferença entre elas é o grau de glicosilação. O ponto isoelétrico foi estimado em aproximadamente 4,55 utilizando o programa de análise de imagens ImageMaster (GE Healthcare).

Conclusão: Os resultados obtidos dão suporte à continuação da pesquisa visando o uso da asparaginase de levedura recombinante como medicamento antileucêmico, já tendo sido iniciados os estudos pré-clínicos in vitro. 